\title{
CRECIMIENTO Y CONDICIÓN OTOÑAL DE LARVAS DE ANCHOÍTA EN LA ZONA COMÚN DE PESCA ARGENTINO-URUGUAYA
}

\author{
Marina V. Diaz ${ }^{1,2}$, Marina Do Souto ${ }^{1,2}$, Daniel Brown ${ }^{1}$, Fabiana Capitanio $^{3}$ y Marcelo Pájaro ${ }^{1}$ \\ ${ }^{1}$ Instituto Nacional de Investigación y Desarrollo Pesquero (INIDEP), \\ Paseo Victoria Ocampo No 1, Escollera Norte, B7602HSA - Mar del Plata, Argentina \\ correo electrónico:mdiaz@inidep.edu.ar \\ ${ }^{2}$ Instituto de Investigaciones Marinas y Costeras (IIMyC), \\ Universidad Nacional de Mar del Plata (UNMdP), \\ Consejo Nacional de Investigaciones Científicas y Técnicas (CONICET), Argentina \\ ${ }^{3}$ Instituto de Biodiversidad y Biología Experimental y Aplicada (IBBEA), \\ Universidad de Buenos Aires (UBA), \\ Consejo Nacional de Investigaciones Científicas y Técnicas (CONICET), Argentina
}

\begin{abstract}
RESUMEN. Se determinó el crecimiento y la condición nutricional de larvas de Engraulis anchoita en la Zona Común de Pesca Argentino-Uruguaya (ZCPAU). La condición se estimó a partir de la relación ARN/ADN estandarizada (RDs) del tronco muscular. El crecimiento se estudió calculando una tasa de crecimiento instantáneo sobre la base de un modelo que incluye RDs y temperatura. Se calculó, además, el crecimiento de los otolitos midiendo el espesor de los últimos tres incrementos completamente formados. Las muestras se obtuvieron en marzo de 2014. Los 12 lances oblicuos que se realizaron con red Bongo y malla de $300 \mu \mathrm{m}$ mostraron presencia de larvas en seis de ellos. Se las separó a bordo y se fijaron en nitrógeno líquido. Posteriormente se las midió, se separaron las cabezas con un bisturí y se liofilizaron los troncos musculares en forma individual $(\mathrm{N}=128)$. Se compararon dos secciones oceanográficas situadas sobre el margen sur y el margen norte de la ZCPAU (COSTAL I y II, respectivamente). La relación RDs de las larvas evidenció una buena condición nutricional. No se observaron diferencias significativas en la condición o el crecimiento entre ambas secciones. Se observó una correlación positiva entre el índice RDs y la talla, por lo que las comparaciones se realizaron considerando el estadio de desarrollo larval. El RDs para las larvas en preflexión en la COSTAL I fue 2,53 $\pm 1,29(\mathrm{n}=53)$ y 2,92 $\pm 1,22(\mathrm{n}=7)$ en la COSTAL II. Para las larvas en flexión fue 3,41 $\pm 1,07(\mathrm{n}=$ 22) y $2,91 \pm 0,86(n=32)$ en las secciones I y II, respectivamente. La elevada condición nutricional de las larvas de anchoíta indica que las características ambientales que se observaron en marzo en el área de estudio serían apropiadas para su crecimiento y supervivencia.
\end{abstract}

Palabras clave: Condición nutricional, relación ARN/ADN, crecimiento, Engraulis anchoita, larvas.

\section{AUTUMN GROWTH AND CONDITION OF ANCHOVY LARVAE IN THE ARGENTINE-URUGUAYAN COMMON FISHING ZONE}

SUMMARY. The growth and nutritional condition of Engraulis anchoita larvae in the Argentine-Uruguayan Common Fishing Zone (AUCFZ) were determined. The condition was estimated considering the standardized RNA/DNA ratio (RDs) of the muscle trunk. Growth was studied calculating an instantaneous growth rate on the basis of a model that includes RDs and temperature. Otoliths growth was also calculated measuring the thickness of the last three fully formed daily increments. Samples were collected in March 2014. The 12 oblique tows performed with a 
Bongo net $300 \mu \mathrm{m}$ mesh size showed presence of larvae in 6 of them. They were separated on board and fixed in liquid nitrogen. Afterwards, they were measured, heads dissected with a scalpel and muscle trunks individually lyophilized $(\mathrm{N}=128)$. Two oceanographic sections located on the southern margin and northern margin of the AUCFZ (COSTAL I and II, respectively) were compared. The RDs ratio of larvae evidenced a good nutritional condition. No significant differences in the larval condition or growth between both sections were found. A positive correlation between the RDs index and size was observed; thus, comparisons were made considering the larval developmental stage. The RDs for pre-flexion larvae in COSTAL I was $2.53 \pm 1.29(\mathrm{n}=53)$ and $2.92 \pm 1.22(\mathrm{n}=7)$ in COSTAL II. For larvae in flexion it was $3.41 \pm 1.07(\mathrm{n}=22)$ and $2.91 \pm 0.86(\mathrm{n}=32)$ in sections I and II, respectively. The high nutritional condition of anchovy larvae indicates that the environmental characteristics observed in March in the study area would be appropriate for their growth and survival.

Key words: Nutritional condition, RNA/DNA ratio, growth, Engraulis anchoita, larvae.

\section{INTRODUCCIÓN}

El estudio de la condición nutricional permite evaluar el estado fisiológico individual de las larvas de peces, que es reflejo de la situación ambiental a la que han estado expuestas. Representa un instrumento útil para determinar dicho estado en distintos ambientes y por consiguiente para determinar zonas de crianza favorables. Además, brinda herramientas para el manejo integral de una población sometida a explotación pesquera, aportando información que podría ser útil para establecer áreas restringidas o períodos de veda (Diaz et al. 2011). Diferentes índices han sido desarrollados para evaluar la condición nutricional en larvas de peces a nivel individual, tisular y celular (Ferron y Leggett 1994). Estos índices operan a diferente escala temporal, siendo el celular el más sensible a cambios ambientales a corto plazo y el individual el que brinda una información más integrada de la influencia ambiental sobre los cambios fisiológicos en las últimas semanas. El índice ARN/ADN es un indicador ecofisiológico muy utilizado en la actualidad, que brinda información acerca del estado fisiológico de las larvas en una escala temporal de horas, dado que provee una medida de la capacidad de biosíntesis celular. El principio teórico de utilizar la relación ARN/ADN es considerar que el número de células (y por lo tanto la cantidad de $\mathrm{ADN}$ ) es virtualmente constante en células somá- ticas, mientras que el ARN presente en los tejidos es directamente proporcional a la síntesis proteica (Bailey et al. 1995; Clemmesen et al. 1997; Diaz y Pájaro 2013).

El estudio del crecimiento diario de larvas de peces representa una herramienta complementaria a los índices de condición nutricional para determinar el estado fisiológico de los organismos y determinar la existencia de zonas favorables para la supervivencia larval dentro de las áreas de cría. El análisis de la microestructura de los otolitos es la metodología utilizada para este fin (Baumann et al. 2003; Brown et al. 2004). Dado que se ha reportado una influencia del crecimiento larval en el reclutamiento al stock de adultos por varios autores para distintas especies de peces marinos (Campana 1996; García et al. 2003; Takasuka et al. 2007), el estudio del crecimiento diario presenta un interés ecológico y pesquero.

La anchoíta, Engraulis anchoita (Hubbs y Marini, 1935), representa el recurso de mayor biomasa potencial en el Atlántico Sudoccidental. Sus altas densidades y amplia distribución la convierten en la especie pelágica de mayor importancia ecológica, cumpliendo un rol clave en las redes tróficas como alimento de varias especies de valor comercial del Mar Argentino (Angelescu 1982; Hansen 2000). Es posible distinguir al menos dos poblaciones de anchoíta en estas latitudes: la bonaerense, situada al norte de los $42^{\circ} \mathrm{S}$ frente a la Provincia de Buenos Aires; y la patagónica, en la región comprendida entre los $42^{\circ} \mathrm{S}$ y $46^{\circ} \mathrm{S}$ (Sánchez 1995). Las áreas de desove y 
cría de estas poblaciones están relacionadas con regiones caracterizadas por discontinuidades oceanográficas de la plataforma argentina (Pájaro et al. 2008). La actividad reproductiva de la anchoíta se inicia en el mes de septiembre en el sector bonaerense y en octubre-noviembre se extiende hacia el sur, cuando comienza la puesta de la población patagónica, alcanzando su máximo en el mes de diciembre (Sánchez 1995; Sánchez y Ciechomski 1995).

Los objetivos de este trabajo fueron estimar la condición nutricional y el crecimiento diario de larvas de E. anchoita capturadas en los márgenes de la Zona Común de Pesca Argentino-Uruguaya (ZCPAU), mediante el índice ARN/ADN y el análisis de incrementos diarios en los otolitos, respectivamente. Dichas variables se analizaron espacialmente y los resultados se discutieron en relación con la disponibilidad de presas potenciales (densidad de larvas nauplii de copépodos) y la presencia de plancton gelatinoso como predadores y/o competidores de las larvas de anchoíta. Si bien parte de los resultados aquí presentados (índice RDs y su índice derivado Gpf) han sido previamente reportados en Negri et al. (2016), en este estudio se realiza una reinterpretación de los mismos en relación con el crecimiento de las larvas de anchoíta.

\section{MATERIALES Y MÉTODOS}

\section{Recolección de muestras}

El material utilizado provino de una campaña de investigación en la ZCPAU, realizada entre el 26 y el 30 de marzo de 2014 a bordo del BIP "Capitán Oca Balda", denominada "Ambiente y plancton en la Zona Común de Pesca en un escenario de Cambio Climático". Se realizaron 12 estaciones de plancton distribuidas en dos transectas perpendiculares a la costa (Figura 1). En cada estación se obtuvieron, mediante arrastres oblicuos desde las cercanías del fondo hasta la superficie, muestras con red Bongo con malla de

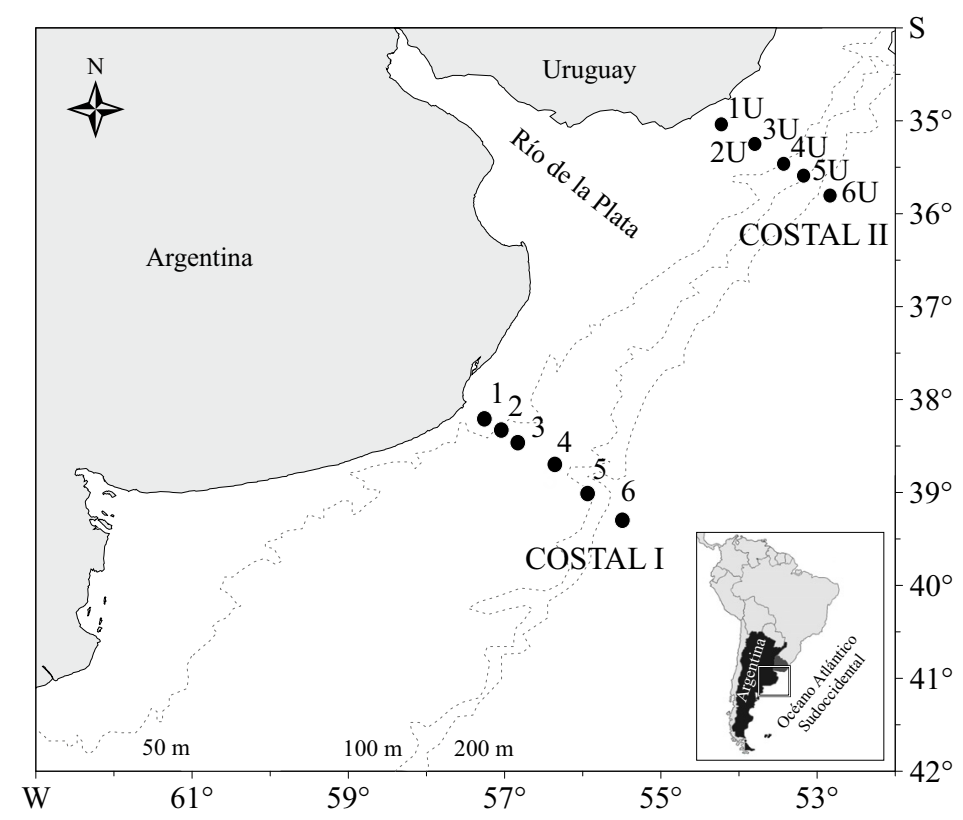

Figura 1. Distribución espacial de las estaciones de muestreo. Figure 1. Spatial distribution of sampling stations. 
$300 \mu \mathrm{m}$ de tamaño de poro, y Mini Bongo con malla de $67 \mu \mathrm{m}$. De las primeras, se separaron larvas destinadas al análisis de condición nutricional y crecimiento diario, que fueron congeladas a bordo en nitrógeno líquido y posteriormente conservadas a $-80{ }^{\circ} \mathrm{C}$ hasta su procesamiento. El remanente de la muestra se fijó en formaldehído al 5\%, y se calcularon las abundancias de larvas y la presencia de plancton gelatinoso. Las muestras obtenidas con Mini Bongo se fijaron en formaldehído al $5 \%$ y se utilizaron para cuantificar la densidad de estadios larvales de copépodos (nauplii).

En cada estación oceanográfica se registraron datos de profundidad, conductividad y temperatura del mar en toda la columna de agua mediante la utilización de un CTD.

\section{Procesamiento de las muestras}

Las larvas fueron descongeladas en el laboratorio, se las fotografió y se midieron las longitudes estándar (LS) al micrómetro empleando el software Axio-Vision. A cada larva se le asignó un estadio de desarrollo de acuerdo con la talla y la flexión de la notocorda (Alheit et al. 1991). Se consideraron larvas en preflexión a las menores a $8 \mathrm{~mm}$ de LS, larvas en flexión a aquellas entre 8-12,9 y larvas en postflexión a las de longitudes mayores a $12,9 \mathrm{~mm}$.

Se removieron las cabezas y conservaron en alcohol etílico $96 \%$, mientras que el tronco larval fue liofilizado durante $24 \mathrm{~h}$. Posteriormente, se determinó el peso seco del tronco al microgramo (PS) empleando una microbalanza Sartorius. Las muestras fueron conservadas a $-80{ }^{\circ} \mathrm{C}$ hasta su procesamiento.

\section{Condición nutricional}

Para la obtención de los índices ARN/ADN se utilizó el protocolo descripto por Caldarone et al. (2001), junto con las modificaciones de Diaz y Pájaro (2012), que se basa en la determinación de las concentraciones de ácidos nucleicos por espectro-fluorescencia. Se procedió en primer lugar a la extracción de ácidos nucleicos mediante la lisis celular por medio de Sarcosil Tris EDTA 1\% y agitación durante $1 \mathrm{~h}$. Luego se llevó a cabo una centrifugación durante $15 \mathrm{~min}$ a $13.400 \mathrm{rpm}$. Del sobrenadante obtenido de cada larva se tomaron $100 \mu \mathrm{l}$, que se llevaron a un volumen de $1.000 \mu \mathrm{l}$ agregando $850 \mu \mathrm{l}$ de Tris EDTA Buffer y $50 \mu 1$ de Bromuro de Etidio $(0,1$ $\mathrm{mg} \mathrm{ml}^{-1}$ ), como fluorocromo. Las determinaciones se realizaron empleando un espectro-fluorómetro Perkin Elmer (Ex: $360 \mathrm{~nm}$ y Em: $590 \mathrm{~nm}$ ). Se registraron dos lecturas para cada larva: una inicial correspondiente a ácidos nucleicos totales, y otra posterior correspondiente al ADN luego del agregado de $50 \mu \mathrm{l}$ de enzima ARNasa (RNasa A de páncreas bovino Sigma R 6513) en una concentración de $20 \mathrm{U} \mathrm{ml}^{-1}$ e incubación durante 30 min a $42{ }^{\circ} \mathrm{C}$. La diferencia entre estas dos lecturas corresponde a la cantidad de ARN presente en cada una de las larvas. La fluorescencia endógena (antes de la adición de bromuro de etidio) resultó insignificante, por lo que no se consideró en cálculos de concentraciones de ácidos nucleicos. De acuerdo con estudios previos realizados empleando larvas de la misma especie (Olivar et al. 2009; Diaz et al. 2011), asumimos que la fluorescencia residual era insignificante por lo que el paso que incluye una digestión por medio de DNAsa fue eliminado en las rutinas de laboratorio.

Para la determinación de la concentración de ácidos nucleicos a partir de las fluorescencias obtenidas, se realizaron interpolaciones de una curva de calibración elaborada previamente a partir de concentraciones conocidas de ADN (ADN lambda, digerido con Hind III, Roche 10236250001) y ARN (ARN 16S-23S de Escherichia coli, Roche 10206938001) crecientes dentro de un rango apropiado. Esta curva se realizó diariamente, previo a la medición de fluorescencia de las larvas, para disminuir posibles errores instrumentales asociados al ambiente. A partir de las concentraciones de ADN y ARN obtenidas se realizó el cociente 
ARN/ADN (RD) para cada larva. La relación promedio entre las pendientes de ADN y ARN de las curvas de calibración fue de 2,69. Todos los valores RD fueron estandarizados (RDs) de acuerdo con el procedimiento descrito por Caldarone et al. (2006), utilizando el valor de pendiente de referencia de 2,4. A su vez, se estimó la tasa de crecimiento $(\mathrm{G})$ para cada larva mediante el modelo RDs-T$\mathrm{G}$ desarrollado por Buckley et al. (2008):

$\mathrm{G}=0,145 \times \mathrm{RDs}+0,0044 \times \mathrm{T} \times \mathrm{RDs}-0,078$

donde $\mathrm{G}$ es la tasa de crecimiento instantáneo y $\mathrm{T}$ es la temperatura medida en el sitio de muestreo. En este caso se utilizó la temperatura a $5 \mathrm{~m}$ de profundidad por considerarla representativa del hábitat de las larvas de anchoíta.

La performance de crecimiento (Gpf) es el cociente entre la tasa de crecimiento observada y la tasa de crecimiento alcanzada por cada larva bajo condiciones óptimas del ambiente y alimentación (Gmax). Dicho cociente proporciona una medida objetiva de la condición larvaria (Buckley et al. 2008). Debido a la falta de un modelo de Gmax para E. anchoita, las tasas de crecimiento de las larvas se compararon con una tasa de crecimiento de referencia (Gref) de acuerdo con Houde y Zastrow (1993), quienes establecieron un modelo multiespecífico basado en 80 especies marinas y estuarinas criadas bajo condiciones óptimas de temperatura:

$\mathrm{G}_{r e f}=0,0106 \times \mathrm{T}-0,0203$

De este modo, los valores de la performance de crecimiento mayores a uno $(\mathrm{Gpf}>1)$ indican una tasa de crecimiento superior a la obtenida bajo condiciones óptimas.

\section{Análisis de los otolitos}

De cada cabeza conservada en alcohol etílico 96\% se extrajeron los otolitos saggitae bajo lupa, se montaron en un medio transparente y se seca- ron durante $48 \mathrm{~h}$ hasta el análisis de la microestructura. La observación en microscopio óptico se realizó en el máximo aumento $(1.000 \mathrm{X})$ con aceite de inmersión. Se determinó la edad de cada individuo, contando los incrementos de crecimiento diario a lo largo del eje mayor del otolito, desde el núcleo hasta el borde. El dato de edad ( $\mathrm{N}^{\mathrm{o}}$ de incrementos diarios) se consideró válido cuando las diferencias entre los otolitos del mismo par eran menores al 10\%. Las mediciones se realizaron con un software de procesamiento digital de imágenes (Brown et al. 2008). Se ajustó un modelo lineal a los datos largo-edad mediante el método de cuadrados mínimos; la pendiente de la regresión se interpretó como la tasa de crecimiento promedio de todos los ejemplares. Complementariamente, y para obtener otro indicador reciente de la condición de las larvas, se determinó el crecimiento de los otolitos a partir de la medición de los espesores de los últimos tres incrementos completamente formados (EM3) (Leonarduzzi et al. 2010), y se calculó una media con su desvío para cada organismo.

\section{Análisis estadístico}

Los valores medios de RDs, Gpf y EM3 se compararon entre ambas transectas (COSTAL I y II) y entre estaciones dentro de cada transecta. Las comparaciones se realizaron mediante un ANCOVA para cada variable, utilizando la talla de las larvas como covariable, para evitar diferencias estadísticas artificiosas debidas a efectos ontogénicos.

\section{RESULTADOS}

En general, la temperatura del mar en la superficie y en el fondo disminuyó desde la costa hacia el talud, excepto en los registros de superficie de las estaciones sobre la plataforma de la COSTAL II, donde varió alrededor de $\operatorname{los} 21^{\circ} \mathrm{C}$ 
(Figura 2 A y B). En la COSTAL I, la temperatura superficial disminuyó desde $18,9{ }^{\circ} \mathrm{C}$ en la costa hasta $12{ }^{\circ} \mathrm{C}$ en el talud; mientras que la salinidad fue superior a 33,85 en toda la columna de agua de las estaciones costeras. Por otra parte, registros de salinidad inferiores a 32 fueron obtenidos en aguas superficiales de las estaciones $1 \mathrm{U}$ a 5U, incrementándose desde la costa hacia mayores profundidades (COSTAL II); valores que se repitieron en el fondo de las estaciones menos profundas ( $1 \mathrm{U}$ a $3 \mathrm{U})$. Las secciones verticales de la COSTAL II (Figura 2 A y C) mostraron, en las estaciones de menor profundidad, la presencia de agua superficial de baja salinidad proveniente del Río de la Plata; en la plataforma media (4U y 5U), la extensión subsuperficial de Agua Subantártica; y al este del borde superior del talud (6U), aguas de origen subtropical con altas temperaturas y salinidad. En la COSTAL I se evidenció el predominio de Agua Subantártica de Plataforma (Lucas et al., 2005), con un mínimo relativo de salinidad en la plataforma central (estación 4), flanqueado por aguas de salinidad relativamente alta, superior a 33,85 en las estaciones costeras ( 1 a 3 ) y en las cercanas al talud (5 y 6) (Figura 2 B y D).

Se detectó la presencia de larvas de anchoíta en 8 de las 12 estaciones estudiadas (Tabla 1). Se estudió la condición nutricional de las larvas recolectadas en las seis estaciones oceanográficas en las que se pudo colectar y congelar suficiente material. Los valores obtenidos para las relaciones RDs y Gpf de las larvas mostraron evidencias de una buena condición nutricional en el área de estudio. Se observó una correlación positiva entre el índice RDs y la talla de los ejemplares (coeficiente de correlación de Pearson $\mathrm{r}=0,26$; $\mathrm{p}<$ 0,001; Figura 3). Por este motivo, se muestran los

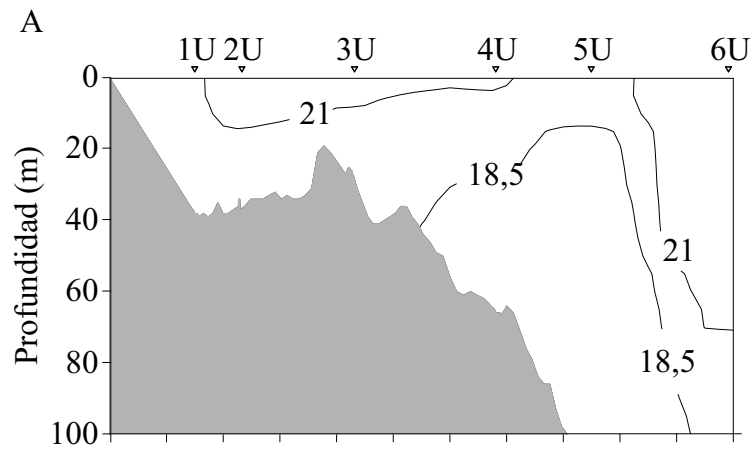

B
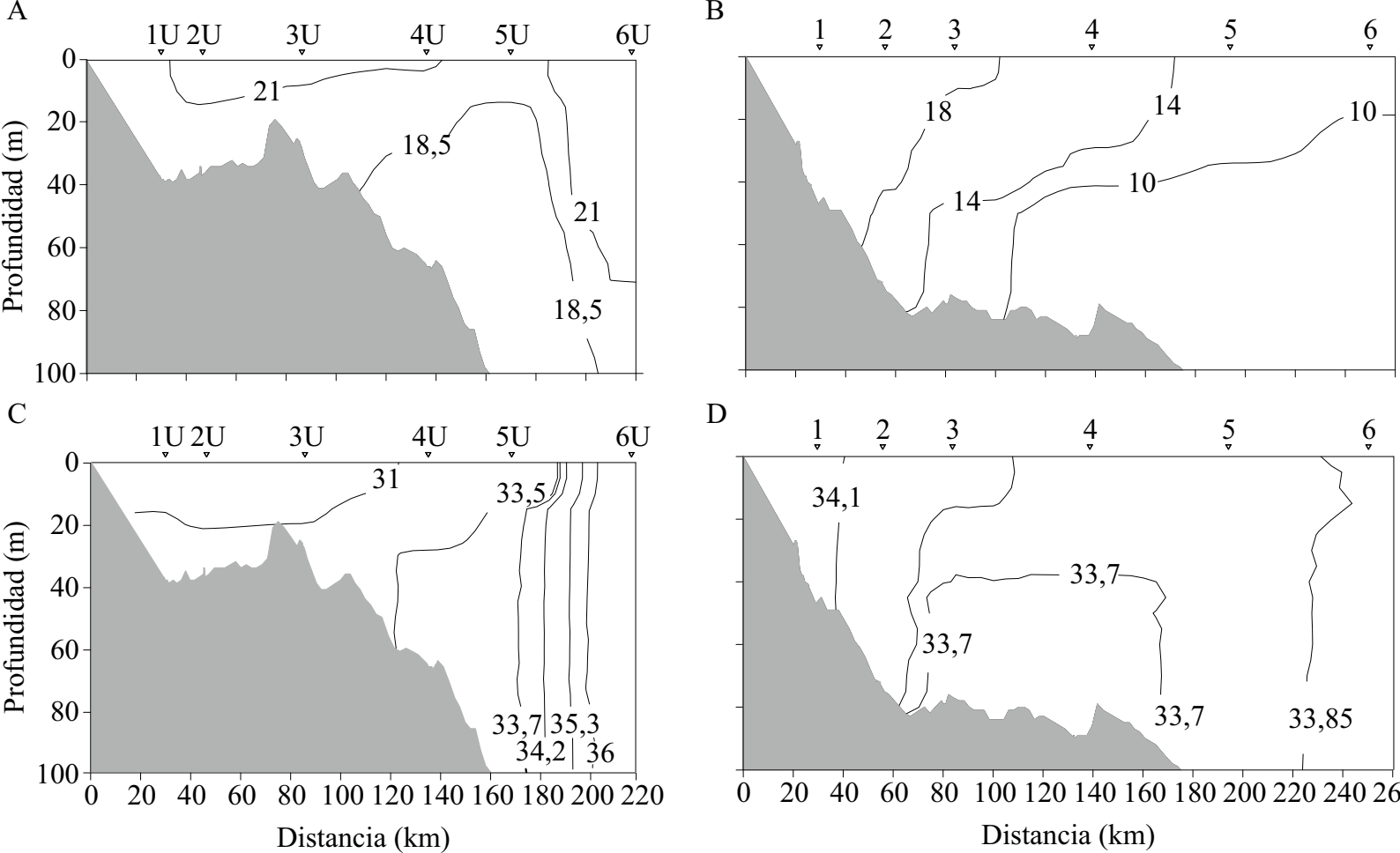

D

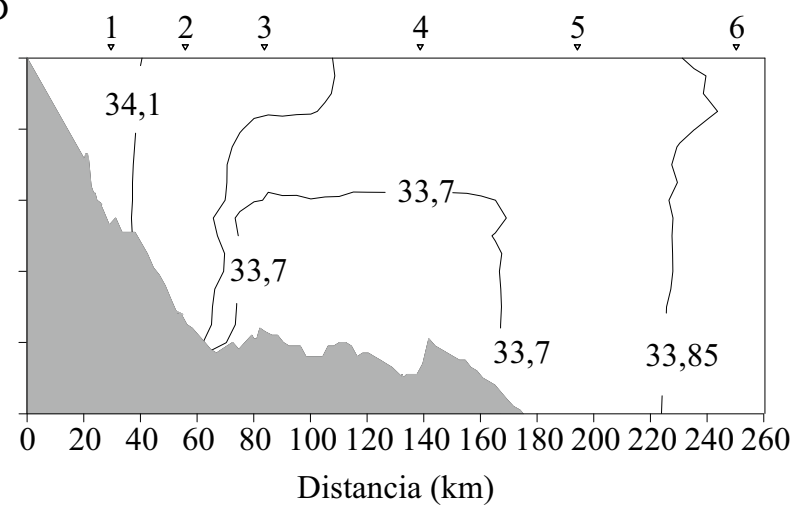

Figura 2. Distribución vertical de temperatura y salinidad en las secciones COSTAL II (A y C) y COSTAL I (B y D). Figure 2. Vertical distribution of temperature and salinity in sections COSTAL II (A and C) and COSTAL I (B and D). 
Tabla 1. Valores medios de la densidad de larvas de anchoíta $\left(\mathrm{L}_{\text {anch }} \mathrm{m}^{-3}\right)$, relación ARN/ADN estandarizada (RDs), performance de crecimiento (Gpf), media del espesor $(\mathrm{mm})$ de los últimos tres incrementos diarios (EM3), rangos de fecha de eclosión, densidad de larvas nauplii de copépodos (nauplii $\mathrm{m}^{-3}$ ) y presencia de zooplancton gelatinoso $(+)$.

Table 1. Mean values of anchovy larvae density ( $L$ anch $\left.\mathrm{m}^{-3}\right)$, standardized RNA/DNA ratio (RDs), growth performance (Gpf), mean thickness $(\mathrm{mm})$ of the last three daily increments (EM3), hatching date ranges, density of copepods nauplii larvae $\left(\right.$ nauplii $\left.\mathrm{m}^{-3}\right)$ and presence of shelly zooplankton $(+)$.

\begin{tabular}{lccccccc}
\hline Estación & $\mathrm{L}_{\text {anch }}{ }^{-3}$ & RDs & Gpf & EM3 & Fecha de eclosión & Nauplii $\mathrm{m}^{-3 *}$ & Presencia gelatinoso \\
\hline 1 & 4,92 & 2,70 & 1,03 & $2,38 \pm 0,92$ & $13 / 03-23 / 03$ & 4.301 & \\
2 & 1,33 & 1,98 & 0,64 & $1,63 \pm 0,39$ & $21 / 03-23 / 03$ & 1.532 & \\
3 & 6,53 & 2,77 & 1,06 & $1,59 \pm 0,32$ & $13 / 03-23 / 03$ & 67 & + \\
4 & 1,55 & 3,17 & 1,28 & $1,47 \pm 0,34$ & $15 / 03-21 / 03$ & 486 & + \\
5 & 0,02 & & & & & 4.560 & + \\
$3 \mathrm{U}$ & 0,07 & & & & & 330 & \\
$4 \mathrm{U}$ & 0,43 & 2,93 & 1,16 & $2,37 \pm 0,58$ & $02 / 03-21 / 03$ & 3.605 & \\
$5 \mathrm{U}$ & 3,18 & 3,00 & 1,20 & $2,68 \pm 0,69$ & $24 / 02-21 / 03$ & 1.236 & \\
\hline
\end{tabular}

*Datos publicados en Negri et al. (2016) y Cepeda et al. (en evaluación).

valores medios para cada estadio de desarrollo larval (Figura 4 A). Los resultados del ANCOVA no evidenciaron diferencias significativas entre las estaciones oceanográficas $(\mathrm{F}=0,45 ; \mathrm{p}=0,81$; coeficiente de correlación con $\mathrm{LS}=0,18 ; \mathrm{p}=$ $0,002)$ ni entre las secciones COSTAL I y II ( $\mathrm{F}=$ 0,$98 ; \mathrm{p}=0,32 ;$ coeficiente de correlación con LS $=0,18 ; \mathrm{p}=0,001)$.

Los índices RDs correspondientes a las larvas en preflexión de la COSTAL II y la COSTAL I fueron respectivamente $2,92 \pm 1,22(\mathrm{n}=7)$ y 2,53 $\pm 1,29(\mathrm{n}=53)$. Asimismo, las larvas en flexión alcanzaron valores de 2,91 $\pm 0,86(\mathrm{n}=32)$ en la sección II y 3,41 $\pm 1,07(\mathrm{n}=22)$ en la sección I.

Los valores medios de la relación Gpf resultaron mayores a 1, exceptuando las larvas en preflexión de la estación 2 de la COSTAL I (Tabla 1; Figura 4 B). De acuerdo con el ANCOVA, no se observaron diferencias significativas entre estaciones oceanográficas $(\mathrm{F}=0,42 ; \mathrm{p}=0,83$; coeficiente de correlación con $\mathrm{LS}=0,10 ; \mathrm{p}=0,002) \mathrm{ni}$ entre las secciones COSTAL I y II ( $\mathrm{F}=0,89 ; \mathrm{p}=$ 0,34 ; coeficiente de correlación con $\mathrm{LS}=0,10 ; \mathrm{p}$ $=0,001)$.

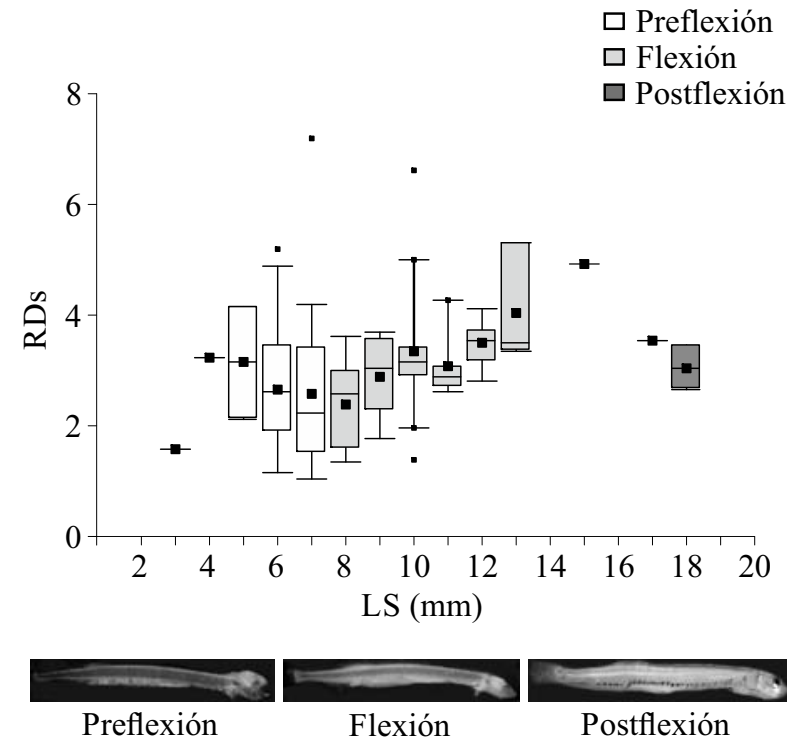

Figura 3. Gráfico Boxplot de la relación ARN/ADN estandarizada (RDs) en función de la longitud estándar (LS) para larvas de Engraulis anchoita. Se indica el estadio de desarrollo larval. Modificado de Negri et al. (2016).

Figure 3. Boxplot of the standardized RNA/DNA ratio (RDs) as a function of standard length (LS) for Engraulis anchoita larvae. The larval developmental stage is indicated. Modified from Negri et al. (2016). 
Los datos largo estándar-edad se representan en un modelo lineal (Figura 5). La pendiente de la relación (valor promedio de la tasa de crecimiento larval) fue de $0,4 \mathrm{~mm}$ día $^{-1}$. La ordenada al origen fue de $4,1 \mathrm{~mm}$, indicando la talla media de depósito del primer incremento diario en los otolitos (edad cero).
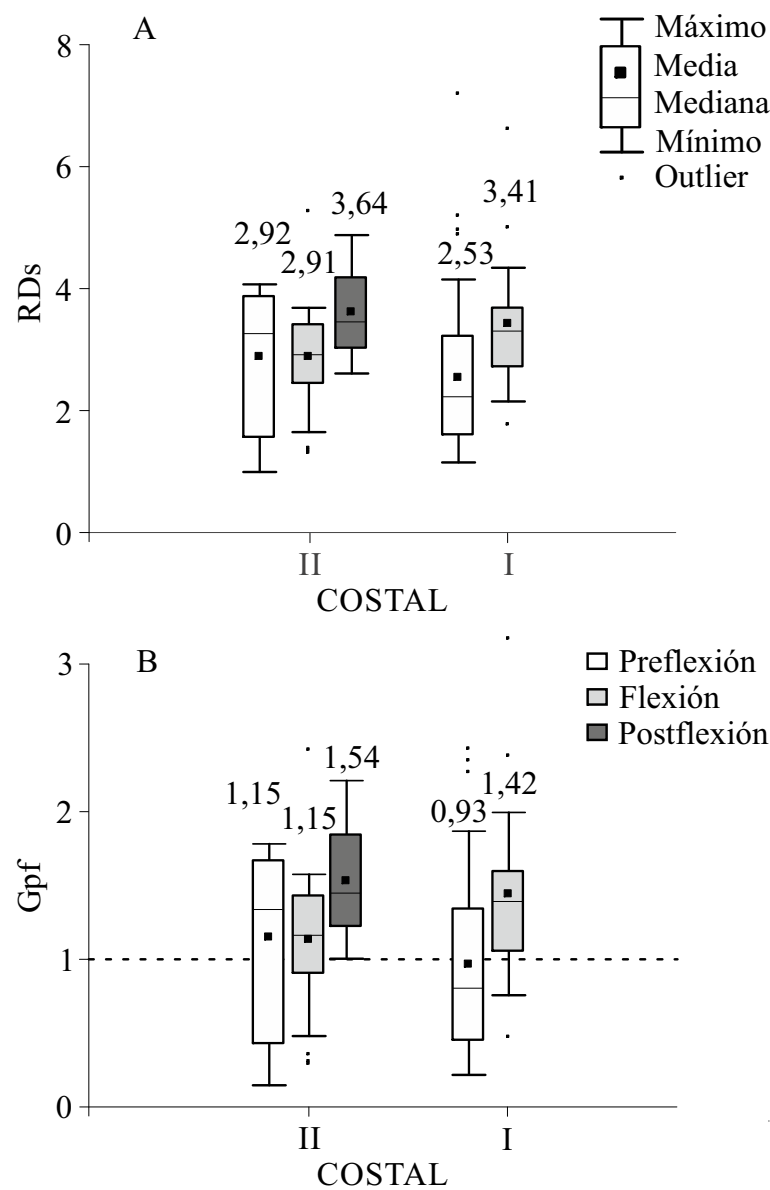

Figura 4. Gráfico Boxplot de (A) la relación ARN/ADN estandarizada (RDs) y (B) la performance de crecimiento (Gpf) para cada sección oceanográfica: COSTAL II y COSTAL I. Sobre las barras se indican los valores medios obtenidos para cada estadio larval de Engraulis anchoita. Tomado de Negri et al. (2016).

Figure 4. Boxplot of $(A)$ the standardized $R N A / D N A$ ratio (RDs) and (B) the growth performance (Gpf) for each oceanographic section: COSTAL II and COSTAL I. On the bars the mean values obtained for each larval stage of Engraulis anchoita are indicated. Taken from Negri et al. (2016).
Los valores medios de EM3 por larva se correlacionaron positivamente con la edad $(r=0,68 ; p$ $<0,01$; Figura 6 ). Los valores medios de los espe-

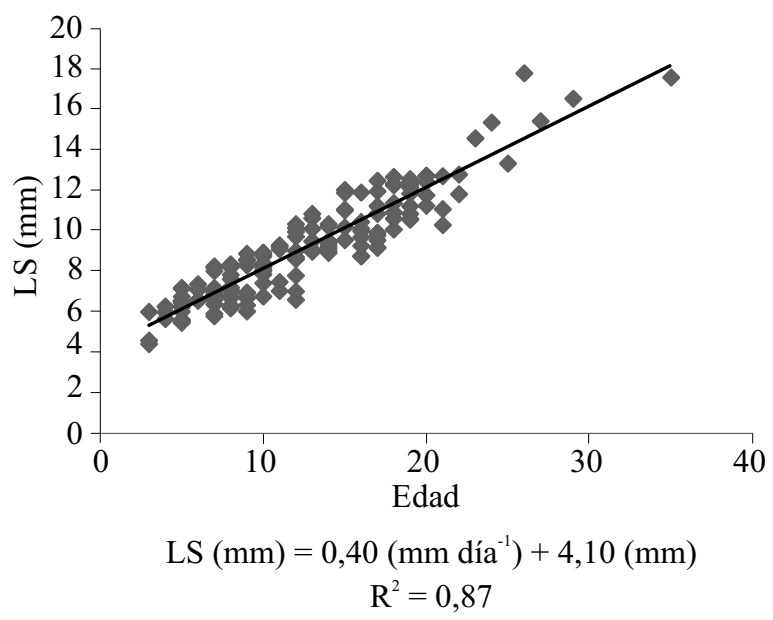

Figura 5. Modelo lineal ajustado a los datos longitud estándar (LS) versus edad (número de incrementos diarios) para las larvas de Engraulis anchoita.

Figure 5. Linear model fitted to standard length data (LS) vs. age (number of daily increments) for Engraulis anchoita larvae.

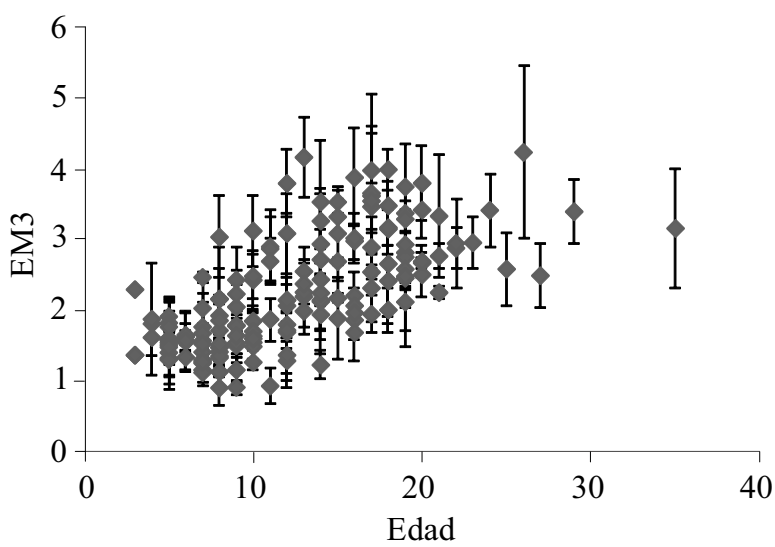

Figura 6. Valores medios del espesor de los últimos tres incrementos completos del otolito (EM3) con su desvío estándar en función de la edad (número de incrementos diarios) para las larvas de Engraulis anchoita.

Figure 6. Mean thickness values of the last three complete otolith increments (EM3) with their standard deviation as a function of age number of daily increments) for Engraulis anchoita larvae. 
sores para cada estadio fueron $1,60 \pm 0,48 \mathrm{~mm}$ (preflexión), 2,58 $\pm 0,81 \mathrm{~mm}$ (flexión) y 3,17 \pm $0,80 \mathrm{~mm}$ (postflexión).

No se hallaron diferencias significativas entre los espesores de los incrementos de los otolitos entre larvas de ambas transectas $(p=0,11)$. Sí se detectaron entre las estaciones 1 y 4 de la sección COSTAL I, donde los espesores más gruesos se observaron en la estación más costera (Tabla 2).

Al graficar los EM3 en función de los valores de RDs para cada organismo, no se halló una tendencia definida entre ambas técnicas (Figura 7). El índice RDs presentó un mayor espectro de valores, mientras que el crecimiento del otolito exhibió un rango más acotado de variación.

\section{DISCUSIÓN}

Los resultados obtenidos evidencian una buena condición nutricional de larvas de anchoíta en el área. No se observaron diferencias en la condición de las larvas colectadas en distintas zonas dentro del área de crianza al comparar entre los diferentes estadios de su desarrollo ontogenético.

Tabla 2. Análisis de covarianza (ANCOVA) correspondiente al espesor de los últimos tres incrementos del otolito (EM3) de larvas de Engraulis anchoita entre estaciones considerando la talla (LS) como covariante (A). Test de Tukey contrastando las estaciones analizadas (B).

Table 2. Covariance analysis (ANCOVA) corresponding to the thickness of the last three otolith increments (EM3) of Engraulis anchoita larvae between stations considering size (LS) as covariant (A). Tukey test comparing the stations analyzed (B).

A

\begin{tabular}{lccrrrr}
\hline F.V. & SC & Gl & CM & F & $P$ & Coef. \\
\hline Modelo & 58,67 & 6 & 9,78 & 35,97 & $<0,0001$ & \\
Estación & 7,87 & 5 & 1,57 & 5,79 & 0,0001 & \\
LS (mm) & 18,67 & 1 & 18,67 & 68,67 & $<0,0001$ & 0,19 \\
Error & 41,32 & 152 & 0,27 & & & \\
\hline Total & 99,99 & 158 & & & & \\
\hline
\end{tabular}

B

\begin{tabular}{lllll}
\hline Estación & Medias & $\mathrm{N}$ & E.E. & \\
\hline 4 & 1,66 & 14 & 0,14 & $\mathrm{~A}$ \\
3 & 2,04 & 39 & 0,10 & $\mathrm{AB}$ \\
$4 \mathrm{U}$ & 2,22 & 10 & 0,17 & $\mathrm{AB}$ \\
2 & 2,31 & 2 & 0,38 & $\mathrm{AB}$ \\
$5 \mathrm{U}$ & 2,34 & 76 & 0,07 & $\mathrm{AB}$ \\
1 & 2,57 & 18 & 0,12 & $\mathrm{~B}$ \\
\hline
\end{tabular}

Test de Tukey: Alfa $=0,05, \mathrm{DMS}=0,75$, Error $=0,27, \mathrm{GL}=152$. Las letras mayúscula diferentes indican medias significativamente diferentes $(p>0,05)$. 


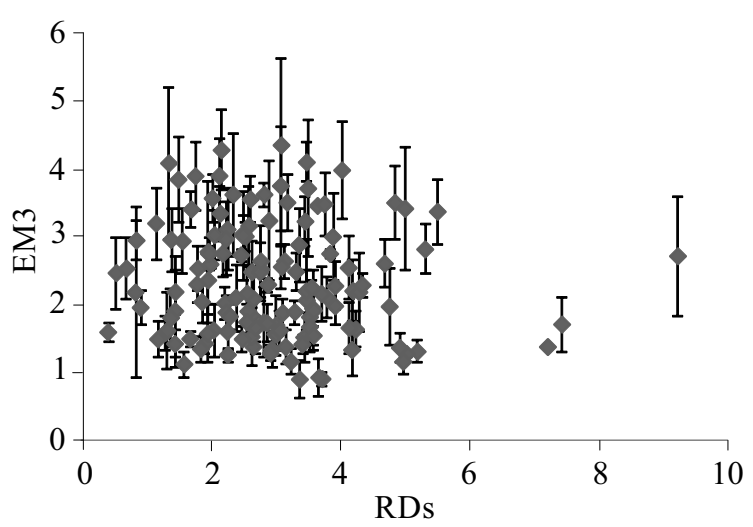

Figura 7. Valores medios del espesor de los últimos tres incrementos completos del otolito (EM3) con su desvío estándar en función del índice de condición nutricional ARN/ADN (RDs) para las larvas de Engraulis anchoita.

Figure 7. Mean thickness values of the last three complete otolith increments (EM3) with their standard deviation as a function of the nutritional condition index RNA/DNA (RDs) for Engraulis anchoita larvae.

Los valores obtenidos fueron similares a los registrados para esta especie en estudios previos realizados en verano (Clemmesen et al. 1997; Diaz et al. 2016), aunque algo menores que los registrados durante la primavera (Diaz et al. 2011) (Tabla 3). Los valores de Gpf, que proporcionan una medida objetiva de la condición larvaria, fueron en general mayores a uno, indicando una tasa de crecimiento mayor a la obtenida bajo condiciones óptimas. Esto indica que las condiciones del área estudiada serían óptimas en cuanto a la disponibilidad de alimento. Sustenta esta idea el hecho que los valores medios obtenidos para la relación RDs resultaron muy superiores a los obtenidos para larvas del Género Engraulis sometidas a condiciones de inanición (Kono et al. 2003).

Es sabido que las larvas de peces que cuentan con una disponibilidad de presas en calidad y cantidad se garantizan una mayor tasa de crecimiento y una condición nutricional mejor (Zenitani et al. 2007). Diaz et al. (2016) detectaron una relación positiva entre el índice RDs y la abundancia de nauplii de copépodos, y una rela- ción negativa entre dicho índice y el volumen de zooplancton gelatinoso. Las larvas de crustáceos de pequeña talla, principalmente de copépodos, se registran en la bibliografía como alimento de los primeros estadios de E. anchoita en la población bonaerense (Viñas y Ramírez 1996; Sato et al. 2011). En referencia al plancton gelatinoso, es considerado un depredador de las larvas de peces (Alvariño 1985; Purcell 1985, 1991), principalmente sobre aquellas que se encuentran en peor condición nutricional y con menor capacidad de escape. Adicionalmente, pueden existir otras relaciones tróficas entre plancton gelatinoso y larvas de peces, como la competencia por alimento y espacio (Purcell y Arai 2001). Una abundancia alta de zooplancton gelatinoso podría dificultar la obtención del alimento de las larvas de E. anchoita, disminuyendo así su condición nutricional. En este estudio se observó una baja densidad de larvas nauplii de copépodos en coincidencia con altos índices RDs y la presencia de zooplancton gelatinoso (estaciones 3 y 4; Tabla 1). Esto podría sugerir que las larvas de anchoíta se alimentan en esas estaciones de otras presas. Viñas y Ramírez (1996) han demostrado que las larvas de anchoíta pueden alimentarse también, aunque en menor medida, de huevos de copépodos, tintínidos, dinoflagelados, larvas de moluscos y diatomeas. Se requerirán futuros estudios de las relaciones tróficas en el área de estudio para establecer las tramas tróficas que involucran a las larvas de anchoíta. Con este fin, se planea realizar un estudio de isótopos estables de $\mathrm{C}$ y $\mathrm{N}$ como marcadores nutricionales.

Los resultados de edad y crecimiento diario de las larvas de anchoíta de este trabajo fueron similares a los registrados en estudios previos (Leonarduzzi et al. 2010; Brown et al. 2013). Dichos autores estimaron tallas de depósito del primer incremento alrededor de $4 \mathrm{~mm}$ y valores promedio de tasa de crecimiento de $0,4 \mathrm{~mm}$ día $^{-1}$. Las diferencias detectadas entre las estaciones 1 y 4 dentro de la COSTAL I serían coincidentes con la 
Tabla 3. Valores medios obtenidos en distintos estudios de la relación ARN/ADN (RD) empleando larvas del Género Engraulis. Se indica el tipo de estudio, la especie y el estadio de desarrollo ontogénico. Tomado de Negri et al. (2016).

Table 3. Mean values obtained in different studies of the RNA/DNA ratio (RD) employing larvae of the Engraulis Genus. The type of study, species and stage of ontogenic development are indicated. Taken from Negri et al. (2016).

\begin{tabular}{|c|c|c|c|c|}
\hline Publicación & Estudio & $\mathrm{RD}$ & Especie & Estadio de desarrollo \\
\hline Kono et al. (2003) & $\begin{array}{l}\text { Laboratorio } \\
\text { Inanición }\end{array}$ & 0,5 & Engraulis japonicus & Preflexión \\
\hline Clemmesen et al. (1997) & $\begin{array}{l}\text { In situ } \\
\text { Fin de primavera }\end{array}$ & $\begin{array}{l}2-3 \\
2-3\end{array}$ & $\begin{array}{l}\text { Engraulis anchoita (Brasil) } \\
\text { Engraulis anchoita (patagonia) }\end{array}$ & $\begin{array}{l}\text { Flexión } \\
\text { Preflexión }\end{array}$ \\
\hline Kanstinger y Peck (2009) & In situ & 3 & Engraulis encrasicolus & Preflexión \\
\hline Diaz et al. (2011) & $\begin{array}{l}\text { In situ } \\
\text { Primavera }\end{array}$ & 4,5 & Engraulis anchoita (bonaerense) & Preflexión \\
\hline Diaz et al. (2016) & $\begin{array}{l}\text { In situ } \\
\text { Verano }\end{array}$ & 2,4 & Engraulis anchoita (patagonia) & Preflexión \\
\hline Este trabajo & $\begin{array}{l}\text { In situ } \\
\text { Otoño }\end{array}$ & 2,6 & Engraulis anchoita (ZCPAU) & Preflexión \\
\hline
\end{tabular}

mayor temperatura y disponibilidad de alimento cerca de la costa. La ausencia de variaciones entre secciones con respecto a los EM3 es coincidente con la homogeneidad entre los valores de RDs y Gpf entre ambas secciones.

Diversos estudios han demostrado que el efectivo bonaerense de anchoíta encuentra en esta zona, principalmente durante la primavera, condiciones apropiadas para su reproducción (Bakun y Parrish 1991; Sánchez y Ciechomski 1995; Pájaro et al. 2008) así como también para el crecimiento y la supervivencia de sus larvas (Bakun y Parrish 1991; Bakun 1996). Apoyando estas hipótesis, en este trabajo hemos observado que la condición nutricional de las larvas de anchoíta fue buena en todas las estaciones de muestreo en las que se detectó la presencia de larvas, indicando que las características ambientales en el mes de marzo serían también apropiadas para el crecimiento y supervivencia de las mismas.

Estudiando el crecimiento diario de larvas de anchoíta del área del frente térmico de marea del litoral patagónico, Brown y Do Souto (2016) observaron un crecimiento más rápido de los ejemplares provenientes de una zona frontal, con respecto a la zona de aguas homogéneas. Dichos autores relacionaron este fenómeno con una mayor abundancia de zooplancton alimento de las larvas. Mediante el análisis de la condición nutricional de las larvas de la misma campaña empleada por Brown y Do Souto (2016), Diaz et al. (2016) detectaron mayores valores de las tasas ARN/ADN en los ejemplares provenientes de la zona frontal. De esta forma, dos metodologías diferentes (la condición nutricional y el análisis de los otolitos) describirían un mismo fenómeno.

La importancia de este tipo de estudios radica en que permite determinar la existencia de zonas favorables para el crecimiento y la supervivencia de las larvas, brindando herramientas para el manejo integral de una población sometida a explotación pesquera. Si bien E. anchoita constituye un recurso poco explotado en la actualidad, presenta una gran potencialidad pesquera para el 
futuro (Pastous Madureira et al. 2009). Por otra parte, en 2011 se concretó la certificación de la pesquería de la población bonaerense de anchoíta (Acta $N^{\circ}$ 31/2011 del Consejo Federal Pesquero), $\mathrm{y}$ actualmente se discute su importancia como especie piloto para aplicar el enfoque ecosistémico en el manejo pesquero. Estos hechos refuerzan la necesidad de realizar estudios interdisciplinarios tendientes a profundizar los conocimientos sobre esta especie.

\section{CONCLUSIONES}

Tanto el análisis de la microestructura de los otolitos como la condición nutricional evidenciaron resultados similares en referencia a la homogeneidad espacial.

La mayoría de los individuos analizados estuvieron en buena condición nutricional. Esto favorecería la supervivencia de las larvas de anchoíta en el área.

La condición nutricional de las larvas y el crecimiento de los otolitos se correlacionaron positivamente con la talla de los ejemplares. Por consiguiente, es importante considerar la ontogenia de las larvas al momento de realizar comparaciones.

\section{AGRADECIMIENTOS}

Los autores expresan su gratitud a María Delia Viñas y Georgina Cepeda por los datos de densidades de larvas nauplii de copépodos, al personal perteneciente al Proyecto "Dinámica del Plancton marino y Cambio Climático" por todo tipo de colaboración brindada durante las campañas de investigación y el procesamiento del material empleado, a las autoridades del Instituto Nacional de Investigación y Desarrollo Pesquero (INIDEP) $\mathrm{y}$ al personal embarcado. Contribución INIDEP $\mathrm{N}^{\mathrm{o}} 2159$.

\section{BIBLIOGRAFÍA}

Alheit J, Ciechomski JD, DJurfeldt L, Ebel C, Ehrlich MD, Elgue JC, Mantero G, MatsuUra Y, Mianzan HW, Nellen W, et al. 1991. SARP Studies on Southwest Atlantic anchovy, Engraulis anchoita, off Argentina, Uruguay and Brasil. ICES Council Meeting papers. Copenhagen. L:46. 80 p.

ALVARIÑO A. 1985. Las surgencias en la región de California-Baja California: Relaciones con el zooplancton y poblaciones de Engraulis mordax (pisces). Invest Mar. 2: 81-102.

ANGELESCU V. 1982. Ecología trófica de la anchoíta del Mar Argentino (Engraulidae, Engraulis anchoita). Parte II. Alimentación, comportamiento y relaciones tróficas en el ecosistema. Contrib Inst Nac Invest Desarr Pesq (Mar del Plata). $N^{o} 409.83$ p.

Bailey KM, Canino MF, Napp JN, Spring SM, Brown AL. 1995. Contrasting years of prey level, feeding conditions, and mortality of larval walleye Pollock Theragra chalcogramma in the western Gulf of Alaska. Mar Ecol Prog Ser. 119: 11-23.

BAKUN A. 1996. Patterns in the ocean. Ocean processes and marine population dynamics. California: University of California Sea Grant. La Paz: Centro de Investigaciones Biológicas del Noroeste. 323 p.

BAKUn A, PARRISH RH. 1991. Comparative studies of coastal pelagic fish reproductive habitats: the anchovy (Engraulis anchoita) of the Southwestern Atlantic. ICES J Mar Sci. 48: 343-361.

Baumann H, Pepin P, Davidson F, Mowbray F, SCHNACK D, DOWER J. 2003. Reconstruction of environmental histories to investigate patterns of larval radiated shanny (Ulvaria subbifurcata) growth and selective survival in a large bay of Newfoundland. ICES J Mar Sci. 60: $243-258$. 
Brown DR, Do Souto M. 2016. Variaciones espaciales en el crecimiento diario de larvas de Engraulis anchoita en Patagonia. Influencia del frente de marea. Inf Invest INIDEP $\mathrm{N}^{\circ}$ 22/2016. 15 p.

Brown DR, Buratti C, Leonarduzzi E. 2008. Incrementos diarios en otolitos de juveniles de Engraulis anchoita provenientes del stock bonaerense. Inf Invest INIDEP N ${ }^{\circ}$ 66/2008. 5 p.

BROWN DR, LEONARDUZZI E, MACHINANDIARENA L. 2004. Age, growth and mortality of hake larvae (Merluccius hubbsi) in the north Patagonian shelf. Sci Mar. 68: 273-283.

Brown DR, Leonarduzzi E, Averbuj A, Livore JP. 2013. Variación temporal de la abundancia de huevos y larvas de Engraulis anchoita en el litoral Norpatagónico entre enero y abril de 2001. Crecimiento y mortalidad larval. Rev Invest Desarr Pesq. 23: 175-192.

Buckley lJ, Caldarone eM, Clemmesen C. 2008. Multi-species larval fish growth model based on temperature and fluorometrically derived RNA/DNA ratios: results from a metaanalysis. Mar Ecol Prog Ser. 371: 221-232.

Caldarone EM, Clemmesen CM, Berdalet E, Miller TJ, Folkvord A, Holt GJ, Olivar MP, Suthers IM. 2006. Intercalibration of four spectrofluorometric protocols for measuring RNA/DNA ratios in larval and juvenile fish. Limnol Oceanogr Methods. 4: 153-163.

Caldarone EM, Wagner M, St. Onge-Burns J, Buckley LJ. 2001. Protocol and guide for estimating nucleic acids in larval fish using a fluorescence microplate reader. Northeast Fisheries Science Center Reference Documents. 11.22 p.

CAMPanA SE. 1996. Year class strength and growth rate in young Atlantic cod Gadusmoruha. Mar Ecol Prog Ser. 135: 21-26.

Clemmesen CM, SÁnChez RP, Wongtschowski C. 1997. A regional comparison of nutritional condition of SW Atlantic anchovy larvae (Engraulis anchoita) based on RNA/DNA ratios. Arch Fish Mar Res. 45: 17-43.
Diaz MV, PÁJAro M. 2012. Protocolo para la determinación de ácidos nucleicos en larvas de peces. Inf Invest INIDEP N ${ }^{\circ} 20 / 2012.9$ p.

Diaz MV, PÁjaro M. 2013. Estudio de la condición nutricional de larvas de la población bonaerense de anchoíta (Engraulis anchoita) en relación con las características hidrográficas del área de crianza. Rev Invest Desarr Pesq. 23: 107-127.

Diaz MV, Pájaro M, Olivar MP, Martos P, MACCHI GJ. 2011. Nutritional condition of Argentine anchovy, Engraulis anchoita, larvae in connection with nursery ground properties. Fish Res. 109: 330-341.

Diaz MV, Do Souto M, Peralta M, Pájaro M, Spinelli M, Saraceno M, Balestrini C, Capitanio F. 2016. Comer o ser comido: factores que determinan la condición nutricional de larvas de Engraulis anchoita de la población patagónica de la especie. Ecología Austral. 26: 120-133.

Ferron A, LegGett WC. 1994. An appraisal of condition measures for marine fish larvae. Adv Mar Biol. 30: 217-303.

García A, Cortés D, Ramírez T, GirÁldez A, CARPENA A. 2003. Contribution of larval growth rate variability to the recruitment of the Bay of Málaga anchovy (SW Mediterranean) during 2000-2001 spawning seasons. Sci Mar. 67: 477-490.

HANSEN JE. 2000. Anchoíta (Engraulis anchoita). En: Bezzi S, Akselman R, Boschi EE, editores. Síntesis del estado actual de las pesquerías marítimas argentinas y de la Cuenca del Plata. Años 1997-1998, con la actualización de 1999. Mar del Plata: Instituto Nacional de Investigación y Desarrollo Pesquero (INIDEP). p. 205-216.

Houde ED, Zastrow CE. 1993. Ecosystem- and taxon-especific dynamic and energetics properties of larval fish assemblages. Bull Mar Sci. 53: 290-335.

Kanstinger P, PeCK MA. 2009. Co-occurrence of European sardine (Sardina pilchardus), an- 
chovy (Engraulis encrasicolus) and sprat (Sprattus sprattus) larvae in southern North Sea habitats: Abundance, distribution and biochemical-based condition. Sci Mar. 73: 141-152.

Kono N, Tsukamoto Y, Zenitani H. 2003. RNA:DNA ratio for diagnosis of the nutritional condition of Japanese anchovy Engraulis japonicus larvae during the first-feeding stage. Fish Sci. 69: 1096-1102.

Leonarduzzi E, Brown DR, SÁnchez R. 2010. Seasonal variations in the growth of anchovy larvae (Engraulis anchoita) on the Argentine coastal shelf. Sci Mar. 74: 267-274.

Lucas A, Guerrero R, Mianzan H, Acha M, LASTA C. 2005. Coastal oceanographic regimes of the Northern Argentine Continental Shelf (34-43으. Estuar Coast Shelf Sci. 65: 405-420.

Negri R, Molinari G, Carignan M, Ortega L, Ruiz MG, Cozzolino E, Cucchi-Colleoni D, Lutz V, Costagliola M, García A, et al. 2016. Ambiente y Plancton en la Zona Común de Pesca Argentino-Uruguaya en un escenario de cambio climático (marzo, 2014). Frente Marit. 24: 251-316.

Olivar MP, Diaz MV, Chícharo MA. 2009. Tissue effect on RNA:DNA ratios of marine fish larvae. Sci Mar. 73: 171-182.

Pájaro M, Martos P, Leonarduzzi E, Macchi GJ, Diaz MV, Brown D. 2008. Estrategia de puesta de la anchoíta (Engraulis anchoita) en el Mar Argentino y Zona Común de Pesca Argentino-Uruguaya. Inf Téc Of INIDEP $\mathrm{N}^{\mathrm{O}}$ 11/2008. 14 p.

Pastous Madureira LS, Castello JP, PrenticeHeRnández C, QueIroz MI, Espírito SANTo ML, Ruiz WA, Raggi Abdallah P, Hansen J, Bertolotti Mi, Manca E, et AL. 2009. Current and potential alternative food uses of the Argentine anchoita (Engraulis anchoita) in Argentina, Uruguay and Brazil. En: HASAN MR, HALWART M, editores. Fish as feed inputs for aquaculture: practices, sustainability and implications. FAO Fisheries and Aquaculture Technical Paper. No 518. p. 269-287.
Purcell JE. 1985. Predation on fish eggs and larvae by pelagic cnidarians and ctenophores. Bull Mar Sci. 37: 739-755.

PuRCELl JE. 1991. A review of cnidarians and ctenophores feeding on competitors in the plankton. Hydrobiologia. 216/217: 335-342.

PURCELl JE, ARAI MN. 2001. Interactions of pelagic cnidarians and ctenophores with fish: a review. Hydrobiologia. 451: 27-44.

SÁNCHEZ RP. 1995. Patrones de distribución espacio-temporal de los estadios embrionarios y larvales de la anchoíta (Engraulis anchoita Hubbs y Marini) a micro y macroescala, su relación con la supervivencia y el reclutamiento [tesis de doctorado]. Facultad de Ciencias Exactas y Naturales, Universidad de Buenos Aires. 672 p.

SÁNCHEZ RP, CIECHOMSKi JDD. 1995. Spawning and nursery grounds of pelagic fish species in the sea-shelf off Argentina and adjacent areas. Sci Mar. 59: 455-478.

SATO NE, HeRnÁndez D, ViÑAs MD. 2011. Hábitos alimentarios de las larvas de Engraulis anchoita (Hubbs \& Marini, 1935) en las aguas costeras de la Provincia de Buenos Aires, Argentina. Lat Am J Aquat Res. 39: 16-24.

TAKasuka A, Oozeki Y, AOKI I. 2007. Optimal growth temperature hypothesis: Why do anchovy flourish and sardine collapse or vice versa under the same ocean regime? Can J Fish Aquat Sci. 64: 768-776.

VIÑAS MD, RAMíREZ FC. 1996. Gut analysis of first-feeding anchovy larvae from Patagonian spawning area in relation to food availability. Arch Fish Mar Res. 43: 231-256.

Zenitani H, Kono N, Tsukamoto Y. 2007. Relationship between daily survival rates of larval Japanese anchovy (Engraulis japonicus) and concentrations of copepod nauplii in the Seto Inland Sea, Japan. Fish Oceanog. 16: 473-478.

Recibido: 07-07-2017

Aceptado: 07-03-2018 